\title{
PATHOLOGY
}

\section{The Contemporary Concept of Significant Versus Insignificant Prostate Cancer}

Ploussard G, Epstein JI, Montironi R, Carroll PR, Wirth M, Grimm MO, Bjartell AS, Montorsi F, Freedland SJ, Erbersdobler A, van der Kwast TH

Department of Urology, Saint-Louis Hospital, APHP, Paris, France; INSERM 955, Team 7, University Paris 12, Créteil, France

Eur Urol. 2011 May 17. [Epub ahead of print]

Context: The notion of insignificant prostate cancer (Ins-PCa) has progressively emerged in the past two decades. The clinical relevance of such a definition was based on the fact that low-grade, small-volume, and organ-confined prostate cancer (PCa) may be indolent and unlikely to progress to biologic significance in the absence of treatment.

Objective: To review the definition of Ins-PCa, its incidence, and the clinical impact of Ins-PCa on the contemporary management of PCa.

Evidence Acquisition: A review of the literature was performed using the Medline, Scopus, and Web of Science databases with no restriction on language up to September 2010. The literature search used the following terms: insignificant, indolent, minute, microfocal, minimal, low volume, low risk, and prostate cancer.

Evidence Synthesis: The most commonly used criteria to define Ins-PCa are based on the pathologic assessment of the radical prostatectomy specimen: (1) Gleason score $\leq 6$ without Gleason pattern 4 or 5, (2) organconfined disease, and (3) tumour volume $<0.5 \mathrm{~cm}(3)$. Several preoperative criteria and prognostication tools for predicting Ins-PCa have been suggested. Nomograms are best placed to estimate the risk of progression on an individualised basis, but a substantial proportion of men with a high probability of harbouring Ins-PCa are at risk for pathologic understaging and/or undergrading. Thus, there is an ongoing need for identifying novel and more accurate predictors of Ins-PCa to improve the distinction between insignificant versus significant disease and thus to promote the adequate management of PCa patients at low risk for progression.

Conclusions: The exciting challenge of obtaining the pretreatment diagnostic tools that can really distinguish insignificant from significant $\mathrm{PCa}$ should be one of the main objectives of urologists in the following years to decrease the risk of overtreatment of Ins-PCa.

\section{Editorial Comment}

With screening for prostate carcinoma, an increasing number of small tumors have been diagnosed. These small tumors may be indolent and unlikely to progress to biologic significance in the absence of treatment. In the past two decades criteria based on needle biopsies have emerged to identify tumors that may behave as indolent (insignificant). The criteria are based on pathologic findings of the radical prostatectomy specimen.

The most used criteria to define insignificant cancer on needle biopsy were proposed by Epstein: 1 . no more than 2 cores with carcinoma; 2 . no more than $50 \%$ of extent on any core; 3 . no Gleason pattern 4 or 5 ; 4. PSA density $<0.15$; and, 5 . clinical stage T1c. A contemporary analysis found that $84 \%$ of patients satisfying these criteria, showed organ-confined disease and Gleason score $<6$ without Gleason pattern 4 or 5 on the surgical specimen (1).

Other studies, however, found a less predictive value for insignificant cancer on radical prostatectomies using Epstein's criteria: 76\%, 69\% and 54\% from Europe (Germany), Asia (South Korea), and Middle East (Epypt), respectively (2-4). Obviously, racial, enviromental, alimentary and methodological 
factors may be involved in these discrepancies.

Due to the relevance of identifying patients harboring indolent tumors, the authors emphasize the need for identifying novel and more accurate predictors of insignificant cancer to improve the distinction between insignificant versus significant disease and thus to promote the adequate management of prostate cancer patients at low risk for progression.

\section{References}

1. Bastian PJ, Mangold LA, Epstein JI, Partin AW: Characteristics of insignificant clinical T1c prostate tumors. A contemporary analysis. Cancer. 2004; 101: 2001-5.

2. Jeldres C, Suardi N, Walz J, Hutterer GC, Ahyai S, Lattouf JB, et al.: Validation of the contemporary epstein criteria for insignificant prostate cancer in European men. Eur Urol. 2008; 54: 1306-13.

3. Lee SE, Kim DS, Lee WK, Park HZ, Lee CJ, Doo SH, et al.: Application of the Epstein criteria for prediction of clinically insignificant prostate cancer in Korean men. BJU Int. 2010; 105: 1526-30.

4. Hekal IA, El-Tabey NA, Nabeeh MA, El-Assmy A, Abd El-Hameed M, Nabeeh A, et al.: Validation of Epstein criteria of insignificant prostate cancer in Middle East patients. Int Urol Nephrol. 2010; 42: 667-71.

Dr. Athanase Billis

Full-Professor of Pathology State University of Campinas, Unicamp

Campinas, São Paulo, Brazil

E-mail: athanase@fcm.unicamp.br 